\title{
Family Violence and Its Implications on Individual and Society
}

\author{
Dr. Maisa Gazei Degeim Alhamed \\ Department of sociology, The University of Jordan, P.O. Box: 842835 Amman, 11354Jordan
}

\begin{abstract}
The present study aimed to identify the severity of family violence implications on individual and society in Jordan. It aimed to identify that from the perspective of the students enrolled at the faculties of educational sciences in Jordanian universities. A simple random sample was selected. It consists from 200 female and male students. Those students were selected from the faculties of educational sciences in the University of Jordan, Al-Balqa' Applied Science and Hashemite University. To meet the study's goals, the researcher developed a fifteen item questionnaire. It was found that the extent of severity of family violence implications on individual and society in Jordan is moderate. That's because the overall mean is 2.96 . It was found that there isn't any statistically significant difference between the respondents' attitudes which can be attributed to their gender or academic year. In the light of the study's results, several recommendations were suggested. For instance, the researcher recommends promoting awareness among students in Jordanian universities about the way of handling family violence in case they experienced it. She also recommends promoting awareness among students in Jordanian universities about the way of helping the ones who suffer from family violence.
\end{abstract}

Keywords: Family violence, society

DOI: $10.7176 / \mathrm{JEP} / 11-3-07$

Publication date: January $31^{\text {st }} 2020$

\section{Introduction}

Family violence has been receiving major attention by researchers. For instance, numerous researchers conducted studies about family violence. Such studies aim at identifying the reasons of family violence and its implications on individual and society. There are many implications for family violence on children. That applies whether family violence is committed by one parent or both parents. The latter implications may include: a decline in the academic performance level, running from the house, addiction, and professional failure in the future.

Family is the most important social unit in society. Through making a family, people can ensure human survival. Family may be defined as a social group which members live in one place. The members of this group assist each other financially. Two members of the family at least have reproductive responsibilities. In this regard, it should be noted that parents in the family are responsible for raising up their children. Therefore, family plays an important role in instilling morals within people. It creates suitable cultural and social environments for raising up children (Bu Alaq, 2017).

Family plays a significant role in developing one's personality and shaping his/her behavior. It exists in all societies and is considered responsible for carrying out several social functions. It has the greatest influence on the lives of individuals and societies. For instance, it enforces control over the acts of individuals and governs the way individuals behave. Through enforcing such a control, the members of the family learn values and traditions and the standards that govern behaviors. Furthermore, family plays an important role in raising up individuals and shaping their personality, and behaviors. It is an important social unit in society. It can influence people. It enables one to identify his/her social role in society (Rashwan, 2003). However, many families today started to refrain from performing their social functions. The values adopted by families today have changed in a negative manner. That led to the spread of deviant and violent behaviors in society. Violent behaviors usually make people aggressive, angry, and oppressed.

Family violence may be called domestic violence. It refers to the use of abusive behaviors and physical power by any member within the family against another family member. It may be attributed to disagreement about issues related to house works. It's called domestic violence because it occurs within the house. It includes spousal violence because it's practiced by a spouse against his/her spouse. Violence -in general- has been existent since ancient times. It may be defined as an aggressive behavior or act which may be performed by an individual or a group in the family. It is practiced in the aim of oppressing another person in the family (Mukhtar, 2004).

Violence is considered a social problem that faces societies. It is committed while there is a family interaction between family members. Social interaction has several patterns. Such patterns include: moving towards people, moving away from them and moving against them. The latter two patterns are considered negative patterns that threaten the social system. The violence-related problems have been increasing due to social, cultural, and financial reasons and reasons related to the dominant values and traditions in society (Al-Ka'by, 2013).

The spread of violence in society shall lead to the increase of the number of deviant acts. It shall lead to a decline in the extent of adopting positive values in society. It shall deprive people from enjoying a good social life and security. In other words, there are many implications for family violence on individual and society (Khalifah, 
There isn't any one fixed definition for family violence. It is difficult to set one fixed definition for this term. That is because family violence is linked to several social, cultural and temporal variables. It's because family violence is linked to the society's tradition. Thus, the criteria that govern the classification of behavior into family violent behaviors and non- family violent behaviors vary from one culture to another. They vary from one period of time to another and from one place to another (Katibi, 2012).

During earlier times, the term (family violence) was linked to the violence committed by a family member against children. Family violence used to be represented mainly in beating, cutting and torturing children by a parent or a caregiver. Later on, this term started to include other forms of violence, such as: children neglect in educational \&medical areas, maltreatment of children, malnutrition, and mental, emotional, sexual, mental, \& physical abuse. Physical abuse against children in the family has been receiving much attention by researchers. Later on, family violence started to include other forms of violence, such as: women abuse (including wife abuse) and abuse against old people. Wife abuse may include: physical abuse (Ameen, 1997).

It's difficult to set one fixed definition for violence. That is because this term is related to many variables and has many dimensions. It is also because violence is a cultural term. To illustrate more, the act that is considered as being violent in one culture, may not be considered as being violent in another culture (Al-Mughazi, 1993).

Psychologists define violence as an instinctive behavior that is associated with aggression and desire for causing damage. They define this term as the use of physical, verbal, or psychological power by an adult family member against another family member (Al-Khouli, 2006). According to sociologists, violence refers to the illegitimate use of power or strength in a manner that affects the will of an individual or a group (Rashwan, 2003).

Family violence is defined as (the use of power illegitimately by an adult family member against another family member. Children are usually the victims of such kind of violence (Berry, 1995).

Family violence refers to physical or psychological violence that is committed by a family member. It causes physical or moral damages. It violates the law. The law punishes the one who commits such kind of violence (Abed Al-Jawad and Al-Batayneh, 2004).

Family or domestic violence exists almost in all families. It is usually committed by husband or the male caregiver. It is the type of violence that is committed the most against women. Women of various classes, age categories, religions, and ethnicities suffer from family violence. The family violence against women is mainly practiced by the male partner. It may involve: swearing, verbal insults, sexual harassment, and physical and, psychological abuse. Psychological abuse may include depriving women from their rights, and undermining her worth (Maki and Ajam, 2008).

There are several theories that aim at identifying the reasons of family violence. These theories shed a light on several aspect, such as: (Al-Ka'by, 2013).

1- The psychiatric aspects: The theories that target such aspects are concerned with attributes of the personality. They suggest that such attributes determine whether a specific person is capable of hurting other or not. Such theories aim at exploring the relationship between personality disorders, mental illness, and addiction from one hand and the results of the damage caused to others from another hand. There are studies that aim at exploring the attributes of the personalities of the victims of violence.

2- The socio-psychological aspects: The theories that target such aspects suggest that violence could be explored through examining the external environmental factors that affect the family. Such factors may include: the structure of the family, and the daily interaction between the family members. Such interaction may predict the occurrence of family violent acts. Such theories shed a light on the pressures enforced on the family and the transition of violent acts from one generation to another.

3- The sociocultural aspects: The theories that target such aspects suggest that there are sociocultural factors that lead to the occurrence of violence. Such factors may include: inequality, cultural standards, family relationships, and the dominant attitudes towards violence.

There are factors that affect the probabilities of committing violent acts. Such factors may include the following ones: (Gazwan, 2015):

1- Individual factors: There are factors related to the individual himself. Such factors may include: depression, low self-confidence level, the nature of the adolescence stage, and the presence of psychological and emotive disorders. They may also include: poor compliance with the social standards, incapability to handle problems, experiencing failure, and deprivation from emotional care. They may include: incapability to control aggressive motives, incapability to have sexual relationships and desire to obtain things that are prohibited. They may include incapability to accept some things (Al-Sanousi, 2002).

2- Addiction: It makes people suffer from psychological problems. Such problems negatively affect one's capability to cope with the surrounding environment. They may lead to experiencing anxiety and stress 
3- Unemployment

4- Having poor faith: Religion aims at regulating people's behaviors and instilling values within them (Omar, 1998).

5- Social factors: Such factors may include: the way in which individuals were raised up. Such a way affects psychological, social, ethical, moral and mental aspects of one's personality. The first few years of one's life have a major impact on his personality formation (Gazwan, 2015).

Family is the most important social unit in society. The presence of violence in the family shall negatively affect the members of the family. It shall negatively affect the whole society.

\section{Statement of the problem and the study's questions:}

Based on the global and local newspaper, the rates of violent acts have been increasing since the end of the $20^{\text {th }}$ century. There isn't any human society that is completely free from violence. Violence has been increasing due to the changes that the contemporary societies have been experiencing. It has been increasing due to the increasing pressures on individual and the spread of depression. It has been increasing due to several economic, social and cultural reasons. For instance, having suffering from bad economic conditions lead to the spread of aggression. In the light of the aforementioned information, the study's problem is represented in the following questions: Q.1 What is the extent of severity of family violence implications on individual and society in Jordan from the perspective of the students enrolled at the faculties of educational sciences in Jordanian universities?

Q.2 Is there any statistically significant difference between the respondents' attitudes which can be attributed to gender or academic year?

\section{The study's objectives}

The present study aimed to identify the extent of severity of family violence implications on individual and society in Jordan from the perspective of the students enrolled at the faculties of educational sciences in Jordanian universities. It aimed to identify whether there is any statistically significant difference between the respondents' attitudes which can be attributed to gender or academic year.

\section{The Study's Significance}

The present study is significant due to the following reasons:

- The present study aimed to explore the severity of the implications of family violence on individual and society in Jordan from the perspective of the students enrolled at the faculties of educational sciences in Jordanian universities. It aimed to meet these goals due to the significance of social security in developing societies in economic, cultural, political and etc..areas.

- The present study enables decision makers in Jordanian universities to identify the extent of severity of family violence implications on individual and society in Jordan. That shall enable those decision makers to make effective decisions to fight against such kind of violence.

- The present study shall enrich the knowledge of curricula developers, and the ones responsible for setting plans that aim at developing the Jordanian family in social areas. It also serves as a good reference for the researchers who want to conduct studies in the future about family violence

\section{Theoretical definitions:}

Family violence: It refers to any violent behavior committed by a family member who has authority against another family member. It involves abuse. It may be represented in spousal violence and violence against parents or grandfathers (Al-Marwati, 2010, 51).

Family: It is a small social group that consists from mother, father, and child/children. The members of this group love each other. The parents in the family are usually responsible for guiding their children, and regulating their behaviors to ensure their compliance with social standards (Khalifah, 2018, 93).

\section{Operational definitions:}

Family violence: It refers to the use of power in an illegitimate manner by an adult family member against another family member

Family: It is a group that consists from mother, father and children. The members of this group share a special relationship with each other.

\section{The study's limits:}

Thematic limits: This study sheds a light on the extent of severity of family violence implications on individual and society in Jordan.

Human limits: This study sampled several BA students who are selected from the faculties of educational sciences in Jordanian universities 
Spatial limits: This study was conducted in the faculties of educational sciences in the University of Jordan, Al-Balqa' Applied Science and Hashemite University.

Temporal limits: This study was conducted during the $1^{\text {st }}$ semester of the academic year 2019/2020

\section{Previous Studies:}

Bu Alaq (2017) aimed to shed a light on family violence and identify its implications on family and society in Algeria. An analytical descriptive approach was adopted. A questionnaire was used to collect data from 50 females who suffered from violence in Algeria. It was found that the spousal violence is mainly committed by the male spouse. It was found that the female spouses didn't experience violence before marriage. The female spouses confirmed that their parents used to refrain from getting into a fight in front of them, except in few cases. 30\% of the respondents confirmed that the male spouses are very violent with them since the engagement period. $70 \%$ of the respondents confirmed that the male spouses are very violent with them since the beginning of marriage. $60 \%$ of the respondents confirmed that they suffered from physical violence. $40 \%$ of the respondents confirmed that they suffered from verbal and psychological violence.

Dubai Foundation for Women \& Children (2016) conducted a study. It aimed to explore the extent of awareness among people in UAE about family violence in UAE. A random stratified sample was selected. 1196 individuals were sampled. They include people who carry the Emirati nationality and people who don't carry it. They are within the range of 15-60 years old. It was found that there is much awareness among people in UAE about family violence. Such high level of awareness is attributed to the active role of modern and conventional media channels. About $42 \%$ of the respondents suggest that family violence is something that can't be accepted at all. About half of the respondents believe that family violence is accepted in some cases. One third of the respondents suggest that the laws are highly capable to prevent people from committing violent acts.

Gazwan (2015) aimed to explore the extent of experiencing family violence by children. He aimed to identify the forms of family violence and its implications on child's personality. He aimed to identify the relationship between this violence and several economic and social variables. The sample consists from 120 kindergarten children who were selected from Iraq. It was found that the percentage of the children who suffer from family, physical, and verbal violent and neglect are high. It was found that the percentage of the children who are negatively affected by violent acts is high. It was found that there is a significant relationship between the extent of experiencing violence by a child from one hand and the number of family members, family financial status, and academic qualification of mother and father from another hand.

Al-Ka'by (2013) aimed to explore the societial factors that lead to the spread of family violence in Qatari society. An analytical descriptive approach was adopted. A questionnaire was used to collect data from respondents. It was found that such factors include: difference between spouses in terms of culture and standards. Such factors also include: the long working hours of the spouses and leaving children without care. They also include: the difference between the spouses in terms of the academic qualifications.

Katibi (2012) aimed to explore the relationship between the extent of experiencing family violence and the psychological alienation level among the eleventh grade students in Rif Dimashq. An analytical descriptive approach was adopted. A questionnaire was used to collect data from 100 female and male eleventh grade students. It was found that there is a significant correlation between the extent of experiencing family violence and the psychological alienation level among the eleventh grade students. It was found that there are statistically significant differences between the respondents' extent of experiencing family violence which can be attributed to gender. The latter differences are for the favor of males. In other words, males experience family violence more than females. It was found that there are statistically significant differences between the respondents' psychological alienation levels which can be attributed to gender. The latter differences are for the favor of females. Thus, that indicates that females experience higher levels of psychological alienation than males.

Abu Zaid (2010) aimed to explore the role of media in fighting against the problems that have been spreading much recently, including family violence. He aimed to improve the communication between institutions in order to fight against the family violence effectively. Interviews were conducted effectively with experts. To be specific, interviews were conducted with 100 experts who are specialized in media, education, family relationship, and psychiatry. It was found that there is a debate over the way of defining family violence. Such a debate is attributed to the variance in terms of cultural and social variables.

Tantawi (2008) aimed to explore the reality of violence against women in Bahrain. An analytical descriptive approach was adopted. A questionnaire was used to collect data from 53 females. Those females were selected through using the random sampling method. They are older than 16 years. Most of the respondents are married. 500 individuals were electronically surveyed (50\% of them are females and 50\% of them are males).It was found that husband is the one who practices violence the most. That applies to families of various income levels. It was found that the lower the family income is, the higher the probabilities of practicing violence will be. It was found that the types of family violence that are practiced the most include: swearing, verbal insults, and degradation.

Chhabra (2018) suggests that domestic violence has many negative impacts on women's health. He adds that 
such violence negatively affects women in physical, and psychological aspects. For instance, family violence may lead to suicide, self-harm acts, mental problems, social isolation, drinking problems and addiction. As for the reasons of family violence, they may include: drinking alcohol, unemployment, early marriage, poverty, and justification for beating wife (Chhabra, 2018)

Lloyd (2018) adds that family violence against children has negative impacts on the educational experiences and outcomes of children. He adds that such violence can make children experience emotional trauma and hinder them from learning. He suggests that children are negative affected when seeing violence committed in front of them at home. He adds that schools play a significant role in fighting against family violence and providing help to the victims of family violence.

\section{The Study's Approach:}

An analytical descriptive approach was adopted. It was adopted to identify the severity of family violence implications on individual and society in Jordan. It aimed to identify that from the perspective of the students enrolled at the faculties of educational sciences in Jordanian universities. It is adopted by many researchers for offering readers a sensory description for things and items. It can be adopted to determine whether certain sensory attributes are deemed accepted or not. It may be adopted by researchers to explore variables and their dimensions and constituents (Lawless and Heymann, 1999).

\section{The Study's Population and Society:}

The population is represented in all the students who are enrolled at the faculties of educational sciences in University of Jordan, Al-Balqa' Applied Science and Hashemite University. A sample was selected through the simple random sampling method. It consists from 200 female and male students. Data about that is displayed below through table (1)

Table (1): The distribution of the study's respondents in accordance with (gender and academic year)

\begin{tabular}{|l|l|r|r|}
\hline Variable & Category & Frequency & Percentage \\
\hline \multirow{5}{*}{ Gender } & Female & 131 & 65.5 \\
\cline { 2 - 4 } & Male & 69 & 34.5 \\
\cline { 2 - 4 } & Total & 200 & $100 \%$ \\
\hline \multirow{5}{*}{ Academic yaer } & $1^{\text {st }}$ year & 37 & 18.5 \\
\cline { 2 - 4 } & $2^{\text {nd }}$ year & 45 & 22.5 \\
\cline { 2 - 4 } & $3^{\text {rd }}$ year & 58 & 29.0 \\
\cline { 2 - 5 } & $4^{\text {th }}$ year & 60 & 30.0 \\
\cline { 2 - 4 } & Total & 200 & $100 \%$ \\
\hline
\end{tabular}

\section{The Study's Instrument}

The researcher developed the study's questionnaire after reviewing the relevant studies. This questionnaire consists from several items that aim to identify the extent of severity of family violence implications on individual and society in Jordan. It aims to identify that from the perspective of the students enrolled at the faculties of educational sciences in Jordanian universities. The initial version of the questionnaire consists from 23 items that shed a light on three areas. These areas are: (unemployment, suicide and addiction).

\section{Validity of the Instrument}

To measure the validity of the questionnaire, the initial version of the questionnaire was passed to 4 experts. Those experts are faculty members. They were selected from the faculties of educational sciences in Jordanian universities. They were asked to assess the questionnaire and provide their opinions about it in terms of language, and relevancy. They were asked to make the necessary changes, such as: additions, deletions, and adjustments. In the light of the experts' opinions, several items were redrafted. The final version of the questionnaire consists from 15 statements. Data about that is displayed below

1- Unemployment: There are 5 statements that shed a light on this area

2- Suicide: There are 5 statements that shed a light on this area

3- Addiction: There are 5 statements that shed a light on this area

The five point Likert scale was adopted. It consists from several categories. These categories are: (to a very great extent, to a great extent, to a moderate extent, to a little extent and to a very little extent).

\section{Reliability of the questionnaire:}

To measure the reliability of the questionnaire, the researcher calculated Cronbach alpha coefficient values. Those values are within the range of $0.75-0.83$. The totalCronbach alpha coefficient value is 0.86 . This value is a good value. Table (2) shows those values 
Table (2): The Cronbach alpha coefficient values of each area

\begin{tabular}{|r|l|l|r|}
\hline No. & Area & Cronbach alpha coefficient value & Number of items \\
\hline 1. & Unemployment & 0.75 & 6 \\
\hline 2. & suicide & 0.77 & 6 \\
\hline 3. & addiction & 0.83 & 6 \\
\hline Total & & 0.86 & 18 \\
\hline
\end{tabular}

\section{Criteria for classifying means:}

The five point Likert scale was adopted. It consists from several categories; to a very great extent, to a great extent, to a moderate extent, to a little extent and to a very little extent). These categories stand for the following scores respectively: 5, 4, 3, 2 and 1 . The criteria used for classifying means are set as follows:

(The maximum value- the minimum value)/ the number of the required categories

$(5-1) / 3=1.33$

1.33 is the interval

2.33 or less: low

2.34-3.67: moderate

3.68 or more: high

\section{The study's variables:}

Intermediate variables: They include: gender and academic year

Dependent variable: It is represented in the severity of family violence implications on individual and society in Jordan. It aimed to identify that from the perspective of the students enrolled at the faculties of educational sciences in Jordanian universities. It is measured through means.

\section{Statistical analysis:}

Several statistical methods were used for analyzing data. For instance, the researcher calculated means, standard deviations. She also conducted the analysis of variance.

\section{Results and discussion}

17.1. Results and discussion related to the study's first questions:

q. 1 What is the extent of severity of family violence implications on individual and society in Jordan from the perspective of the students enrolled at the faculties of educational sciences in Jordanian universities?

To answer this question, means and standard deviations were calculated. These values are identified through table (3) below

Table (3): The extent of severity of family violence implications on individual and society in Jordan from the perspective of the students enrolled at the faculties of educational sciences in Jordanian universities

\begin{tabular}{|l|l|r|r|r|l|}
\hline No. & Area & Mean & Std. & Rank & Level \\
\hline 3 & Addiction & 3.20 & 1.28 & 1 & Moderate \\
\hline 2 & Suicide & 2.87 & 1.01 & 2 & Moderate \\
\hline 1 & Unemployment & 2.83 & .94 & 3 & Moderate \\
\hline & Total & 2.96 & 1.03 & & Moderate \\
\hline
\end{tabular}

Based on table (3), it was found that the extent of severity of family violence implications on individual and society in Jordan is moderate. That is because the overall mean is 2.96 . The total standard deviation is 1.03 . It was found that the addiction area is ranked first due to showing a mean of 3.20 which is moderate. The standard deviation of the latter area is 1.28. It was found that the suicide area is ranked second due to showing a mean of 2.87 which is moderate. The standard deviation of the latter area is 1.01. It was found that the unemployment area is ranked third due to showing a mean of 2.83 which is ranked third. The standard deviation of the latter area is 0.94 .

The latter result is attributed to the fact that family violence leads to the spread of social problems, such as: (unemployment, suicide and addiction). It's attributed to the fact that family violence leads to breaking down the family relationships and weakening the control enforced by parents on sons and daughters. It's attributed to the fact that family violence leads to the commitment of deviant acts and experiencing depression by sons and daughters. It should be also noted that addiction and deviant acts make one lose his job. That shall negatively affect the whole society.

Means and standard deviations were calculated for each statement of the questionnaire. They are presented through table (4) below: 
Table (4): Means and standard deviations for each statement of the questionnaire

\begin{tabular}{|c|c|c|c|c|c|}
\hline No. & Statement & Mean & Std. & Rank & Level \\
\hline \multicolumn{6}{|c|}{ Unemployment } \\
\hline 2 & Family violence increase the probabilities of losing job & 2.90 & .99 & 1 & Moderate \\
\hline 3 & $\begin{array}{l}\text { Family violence negatively affects the probabilities of getting a } \\
\text { promotion }\end{array}$ & 2.80 & .92 & 2 & Moderate \\
\hline 4 & Family violence negatively affects one's performance at work & 2.74 & .98 & 3 & Moderate \\
\hline 5 & Family violence negatively affects one's desire to work & 2.61 & .70 & 4 & Moderate \\
\hline 1 & $\begin{array}{l}\text { The increase of the unemployment rate leads to the increase of the } \\
\text { family violence rate }\end{array}$ & 2.38 & .97 & 5 & Moderate \\
\hline \multicolumn{2}{|r|}{ Total (Unemployment) } & 2.83 & .94 & & Moderate \\
\hline \multicolumn{6}{|c|}{ Addiction } \\
\hline 8 & $\begin{array}{l}\text { Experiencing family violence increases the probabilities of becoming } \\
\text { addicted }\end{array}$ & 2.77 & .87 & 1 & Moderate \\
\hline 6 & $\begin{array}{l}\text { Addiction is widely spread among the families that suffer from } \\
\text { violence }\end{array}$ & 2.73 & .90 & 2 & Moderate \\
\hline 7 & $\begin{array}{l}\text { Family violence reduces the probabilities of having people treated } \\
\text { from addiction }\end{array}$ & 2.70 & .84 & 3 & Moderate \\
\hline 9 & Family violence has negative implications on family and society & 2.66 & .87 & 4 & Moderate \\
\hline 10 & Family violence increases the number of addicts in society & 2.64 & .82 & 5 & Moderate \\
\hline \multicolumn{2}{|c|}{ Total (addiction) } & 3.20 & 1.28 & & Moderate \\
\hline \multicolumn{6}{|c|}{ Suicide } \\
\hline 11 & $\begin{array}{l}\text { Suicide rates is widely spread among the families that suffer from } \\
\text { family violence }\end{array}$ & 3.13 & 1.21 & 1 & Moderate \\
\hline 12 & Family violence increases the suicide rates & 2.90 & .99 & 2 & Moderate \\
\hline 15 & $\begin{array}{l}\text { Family violence negatively affects the male and female family } \\
\text { members }\end{array}$ & 2.77 & .94 & 3 & Moderate \\
\hline 13 & Family violence negatively affects one's desire to live optimistically & 2.73 & .87 & 4 & Moderate \\
\hline 14 & Family violence makes sons and daughters experience depression & 2.51 & .70 & 5 & Moderate \\
\hline \multicolumn{2}{|c|}{ Total (Suicide) } & 2.87 & 1.01 & & Moderate \\
\hline
\end{tabular}

Based on table (4), the means that concern the unemployment area are within the range of (2.38-2.90. The mean of statement (2) is 2.90 which is moderate and ranked first. The latter statement states the following: (Family violence makes one lose his job). The mean of statement (1) is 2.38 which is moderate and ranked last. The latter statement states the following: (The increase of the unemployment rate leads to the increase of the family violence rate). The total mean of the unemployment is 2.83 which is moderate.

Based on table (4), the means that concern the addiction area are within the range of (2.64-2.77). The mean of statement (8) is 2.77 which is moderate and ranked first. The latter statement states the following: (Experiencing Family violence increases the probabilities of becoming addicted). The mean of statement (10) is 2.64 which is moderate and ranked last. The latter statement states the following: (Family violence increases the number of addicts in society). The total mean of the addiction is 3.20 which is moderate.

Based on table (4), the means that concern the suicide area are within the range of (2.51-3.13). The mean of statement (11) is 3.13 which is moderate and ranked first. The latter statement states the following: (Suicide rates is widely spread among the families that suffer from family violence). The mean of statement (14) is 2.51 which is moderate and ranked last. The latter statement states the following: (Family violence makes sons and daughters experience depression). The overall mean of the suicide area is 2.87 which id moderate

\subsection{Results and discussion related to the study's second questions:}

q.2 Is there any statistically significant difference between the respondents' attitudes which can be attributed to gender or academic year?

To answer this question, means and standard deviations were calculated for identifying the respondents' attitudes in accordance with their gender and academic year. Multivariate analysis of variance (MANOVA) was conducted to identify whether the differences between the respondents' attitudes are statistically significant or nor. 
Table (5): means and standard deviations for the respondents' attitudes in accordance with their gender and academic year

\begin{tabular}{|l|l|r|r|r|}
\hline Variable & Category & Frequency & Mean & Std. \\
\hline \multirow{3}{*}{ Gender } & Female & 131 & 3.03 & 1.05 \\
\cline { 2 - 5 } & Male & 69 & 2.84 & 1.00 \\
\hline \multirow{5}{*}{ Academic yaer } & $1^{\text {st }}$ year & 37 & 2.90 & 1.03 \\
\cline { 2 - 5 } & $2^{\text {nd }}$ year & 45 & 2.66 & .98 \\
\cline { 2 - 5 } & $3^{\text {rd }}$ year & 58 & 3.06 & 1.04 \\
\cline { 2 - 5 } & $4^{\text {th }}$ year & 60 & 3.13 & 1.05 \\
\hline
\end{tabular}

Based on table (5), it appears that there are differences between respondents' attitudes which can be attributed to gender and academic year. To identify whether these differences are statistically significant or not at the statistical significance level of $(a=0.05)$, the researcher conducted the multivariate analysis of variance (MANOVA). The results of the latter analysis are displayed through table (6) below:

Table (6): The results of the multivariate analysis of variance (MANOVA)

\begin{tabular}{|r|r|r|r|r|r|}
\hline Variable & Sum of squares & Df. & Sum of squares & F value & Sig. \\
\hline Gender & 1.241 & 1 & 1.241 & 1.412 & .236 \\
\hline $\begin{array}{r}\text { Academic } \\
\text { year }\end{array}$ & 5.214 & 3 & 1.738 & 1.977 & .119 \\
\hline Error & 168.752 & 192 & .879 & & \\
\hline Total & 1977.000 & 200 & & & \\
\hline
\end{tabular}

$(*)$ : This sign means that the value is statistically significant at the statistical significance level of $(a=0.05)$

Based on table (6), it was found that there isn't any statistically significant difference between the respondents' attitudes which can be attributed to gender. That's because the relevant significance value is 0.236 which is not statistically significant. The latter result may be attributed to the fact that family violence negatively affect the female and male family members. It may be attributed to the fact that family violent acts are not committed against a specific gender only. In fact, family violent acts are committed against female and male family members.

The latter result is inconsistent with the result concluded by Katibi (2012). For instance, the latter researcher concluded that there are statistically significant differences between the respondents' extent of experiencing family violence which can be attributed to gender. The latter differences are for the favor of males. In other words, males experience family violence more than females.

Based on table (6), it was found that there isn't any statistically significant difference between the respondents' attitudes which can be attributed to the academic year. That's because the relevant significance value is 0.119 which is not statistically significant. The latter result may be attributed to the fact that family violent acts may be committed against any one regardless of his academic qualification or academic year.

\section{Conclusion and Recommendations:}

It was found that the extent of severity of family violence implications on individual and society in Jordan is moderate. That is because the overall mean is 2.96 . That means that several measures must be taken by the Jordanian government to fight against family violence. It also means that the Jordanian society suffers from family violence. It was found that there isn't any statistically significant difference between the respondents' attitudes which can be attributed to their gender. It was found that there isn't any statistically significant difference between the respondents' attitudes which can be attributed to their academic year. That's because family violence may be experienced by all people regardless of their ethnicity, gender, academic qualification, income, culture and etc.. In other words, any one in society may become a victim for family violence regardless of his/her demographic attributes. Therefore, there must be public bodies in Jordan that supervise the way in which parents and caregivers take care of children. There must be also public bodies in Jordan that provide care to females who suffer from family violence.

In the light of the study's results, the researcher recommend the following:

- Promoting awareness among students in Jordanian universities about the way of handling family violence in case they experienced it.

- Promoting awareness among students in Jordanian universities about the way of helping the ones who suffer from family violence.

- Motivating students to participate in voluntarily activities that aim at providing help for the victims of family violence.

- $\quad$ Conducting more studies about family violence and its implications with targeting other societies and other variables 


\section{References}

Al-Ka'by, (2013).Societal factors affecting family violence in the Qatari Society. The Journal of Damascus University. 29 (3)

Ameen, Fatmi (1997). Scale for measuring family violence. Dirasat Journal for Social Service and Human Sciences (Issued by Hulwan University). Issue No. 5

Al-Mughazi, Duha Abed Al-Ghafar (1993).Family violence: From a sociological perspective. The sixth scientific conference in Cairo

Dubai Foundation for Women \& Children (2016). A survey about the extent of awareness about family violence inEmirate. Publisher: Al-Dira Center for Studies and Surveys

Khalifah, Ibtisam Salem (2018). The manifestations of family violence against children and its impacts on society and strategies to fight against it. The Journal of the Faculty Education. Issue 12

Al-Marwati, Nayef bin Mohammad (2010). Family violence. The Arab Journal for Security and Educational Studies (this journal issued by Naif Arab University for Security Sciences in Riyad, KSA). 26(2010)

Bu Alaq, Kamal (2017). Family violence and its impact on family and society in Algeria: A field study in the Department of Forensic Science in Muslim Al-Tayeb Hospital. Unpublished PhD dissertation. Wahran University.

aRashwan, Husaain Abed Al-Hameed (2003). Family and society: A sociological study targeting family. Shabab Al-Jame'a publication and distribution house. Alexandria. Egypt

Mukhtar, Wafeeq Safwat (2004). Family and methods for raising up children. Dar Al-Elem publication and distribution house. Cairo

Al-Khouli, Mahmoud Saeed Ibrahim (2006). Violence in daily life: Patterns of interaction. Al-Isra' publication and distribution house. Cairo

Maki, Raja and Ajam, Sami (2008). Violence: The illegitimate and legitimate violence. Al-Mu'asasehAl-Jame'ye for Studies and Publication. Beirut. Lebanon

Abu Zaid, Othman (2010). Media channels and family violence. Unpublished MA thesis. Naif Arab University for Security Sciences. Riyad. KSA

Tantawi, Amal (2008). Field survey. Bahrain Center for Studies and Research. Bahrain

Gazwan, Anas Abbas (2015). The family violence committed against children and its implications on personality: A field social study in Al-Hallah City. Babal University Journal: Human Sciences. 23 (4).

Katibi, Mohammad Izzat (2012). The family violence committed against sons and daughters and its relationship with psychological alienation: A field study targeting a sample consisting from several $11^{\text {th }}$ grade students in Rif Dimashq. The Journal of Rif Dimashq. 28(1).

Abed Al-Jawad, Hani and Al-Batayneh, Mohammad (2004). The attributes of family violence committers and victims in Jordan. The Higher Council for Science and Technology (HCST). Amman. Jordan

Berry, D. B. (1995) The Domestic violence: Source book everything you need to know (3rd). Lowell House, NTc, contemPorary Publishing Group, Inc, Los Angeles, U.S.A.

Lawless H.T., and Heymann H. (1999) Descriptive Analysis. In: Sensory Evaluation of Food. Food science text series. Springer, Boston, MA

Chhabra, S (2018) Effects of Societal/Domestic Violence on Health of Women. Women's Health Reproductive Medicine. 2(1:6)

Lloyd, M. (2018). Domestic Violence and Education: Examining the Impact of Domestic Violence on Young Children, Children, and Young People and the Potential Role of Schools. Frontiers in Psychology. Vol. 9

Acknowledgment:

The researcher of the present study would like to thank her family members and instructors for providing her with assistance, care and support. 